\title{
Genital abnormalities associated to lack of uterine adenogenesis or endometrial gland dysgenesis of female dromedary camels (Camelus dromedarius)
}

\author{
Djallel Eddine Gherissi ${ }^{1,2^{*}}$, Ramzi Lamraoui ${ }^{2}$, Faycel Chacha ${ }^{2}$, Zoubir Bouzebda ${ }^{1,2}$, Farida Afri Bouzebda ${ }^{1,2}$ and \\ Christian Hanzen ${ }^{3}$ \\ ${ }^{1}$ Department of Veterinary sciences, University of Souk-Ahras. Souk Ahras 41000, Algeria \\ ${ }^{2}$ Laboratory of Animal Productions, Biotechnologies and Health. University of Souk-Ahras. Souk Ahras 41000, \\ Algeria \\ ${ }^{3}$ Faculty of Veterinary Medicine, Department of Fundamental and Applied Research for Animal and Health. \\ University of Liège Abstract, 4000 Liège, Belgium
}

\begin{abstract}
Background: The developmental disruption of the müllerian duct and the endometrial dynamic can generate genital lesions that could contribute to infertility.

Aim: This paper discusses two cases of genital conditions associated to endometrial gland pathologies in nulliparous female camels.

Methods: Macroscopic examinations and histopathological description were performed on congenital and acquired genital abnormalities with endometrial gland anomalies.

Results: The first case is endometrial gland agenesis associated to unilateral uterine aplasia, and the second case is endometrial gland dysgenesis associated to metritis. The prevalence of each case is estimated to be $0.6 \%$. The most specific microscopic features associated to the endometrial gland agenesis were the presence of endometrial stromal proliferation and homogenous hyalinization of the myometrium. The acute metritis was associated to endometrial-activated stroma with focal infiltration with inflammatory cells on the endometrium and myometrium and the spontaneous endometrial gland dysgenesis.

Conclusion: This study reveals the importance of congenital abnormalities during the routine reproductive examination of peripubertal animals, as well as the association of histopathological complementary examination for the research functional and inflammatory anomalies of the uterus. Genetic screening of breeders would be very important in the search for genetic risk factors associated with these congenital pathologies, which can be disseminated by reproductive biotechnologies.
\end{abstract}

Keywords: Adenogenesis, Camel, Metritis, Uterine aplasia, Uterine glands.

\section{Introduction}

The vast array of structural anomalies seen in Müllerian duct defects results from interruption or dysregulation in Müllerian duct development at various stages of morphogenesis (Gray et al., 2001a). The well-known factors, such as intra- and extrauterine elements, genetics, and teratogens, have been associated with Müllerian duct anomalies (Golan et al., 1989; Spencer et al., 2019). The genetics of Müllerian duct anomalies are complex. In general, they occur sporadically, and the most familial cases are multifactorial. Other modes of inheritance, including autosomal dominant, autosomal recessive, and X-linked disorders, also exist. Müllerian anomalies may also represent a component of a multiple malformation syndrome (Carson et al., 1983; Shulman and Elias, 1988; Verp et al., 1983).

The unicornuate uterus is the result which completely or incompletely fails to elongate the Müllerian duct and may arise as a consequence of agenesis involving all structures derived from one urogenital ridge
(Demir et al., 2007; Haydardedeoglu et al., 2006; Mülayim et al., 2003). This anomaly was reported in farm animals such as riverine buffalo (Azawi and Ali, 2011; Chethan et al., 2017) and in the canine population with prevalence ranging from $0.02 \%$ to $0.05 \%$ (McIntyre et al., 2010; Roberts, 1971). The process of endometrial gland development is called adenogenesis. The inhibition of the development of these glands through gene mutation, epigenetic strategies, endocrine, and cellular mechanisms results in infertility (Gray et al., 2001b; Witkowski et al., 2017). Cases of total intrauterine gland developmental agenesis were reported in ewes, bitch, and mare (Chethan et al., 2017; Dockweiler et al., 2017; Gray et al., 2002).

In mice, it has been established that several genes aside from the Hoxa and Wnt families have to regulate Müllerian duct differentiation (Connell et al., 2013). A temporal and spatial variation in expression of the Wnt and Hoxa family genes may explain the diversity of uterine shapes, endometrial glands agenesis, 
disorganized myometrium, and reduction in stromal compartment, suggesting different degrees of Müllerian ducts fusion (Massé et al., 2009; Miller and Sassoon, 1998; Warot et al., 1997). Catenin (cadherin-associated protein), beta 1 (Ctnnb1) produces the protein $\beta$-catenin and is a downstream effector of the Wnt family genes. The knockout of this protein leads to the absence of uterine glandular tissue and epithelium that resembles that of the vagina (Jeong et al., 2009). Finally, forehead box A2 (Foxa2) has been identified as an important regulatory gene in gland formation as ablation of Foxa2 leads to glandular agenesis (Jeong et al., 2010). As reported above, the pathways that orchestrate Müllerian duct formation and differentiation are obviously complex. The endometrial gland dysgenesis was reported to occur during the nonbreeding season of the camel species (Ali et al., 2017). Such reduced endometrial gland numbers were associated to pregnancy rate decease in adult heifers and ovine Uterine Gland Knockout (UGKO) (Floyd et al., 2001; Gray et al., 2000) and result in fibrotic lesions in mare endometrium (Gerstenberg et al., 1999).

The bibliographic data in camel species lack information on the adenogenesis failure. In the present study, we try to evaluate the prevalence of occurrence of the endometrial gland agenesis associated to the uterine horn aplasia and the endometrial gland dysgenesis associated to uterine infection in nulliparous female dromedary camels. The histopathological descriptions of these genital abnormalities were also considered.

\section{Materials and Methods}

\section{Study region}

The experiment was conducted at El Oued region situated in the extreme arid region of southeastern Algeria (Latitude: $33^{\circ} 5^{\prime}$ and Longitude: $6^{\circ} 11^{\prime}$, average altitude of $80 \mathrm{~m}$, average annual temperature of $25^{\circ} \mathrm{C}$, and mean annual precipitation of $80 \mathrm{~mm}$ ).

\section{Animals}

This study was conducted between February 2013 and August 2014. A total of 165 female camels were selected by systematic random sampling technique from the local transhumant herds of Sahraoui breed. They have normal clinical conditions without clinically apparent disease. The age of these animals varies between 6 and 20 years, and their body condition ranges from 2 to 4 on a scale of 5 according to Faye et al. (2001). The reproductive histories of the studied animals were unknown. All the animals were culled from pastoral herds and intended for the production of meat for human consumption. A general examination of each animal was undergone with special attention to genital locoregional signs (Hanzen, 2015a; Tibary, 2007).

\section{Macroscopic and histopathologic examination}

Following the slaughter of each animal, the genital tract topography was determined according to descriptions reported by Ali (2010) and Hanzen (2015a). The genital tract was separated carefully from the pelvis and surrounding structures. A standard genital examination was adapted for an in vitro diagnosis. Macroscopic examination was performed thorough inspection and palpation in a progressive ascending sequence (vulva, vagina, cervix, uterus, oviducts, and ovaries) (Hanzen, 2015a; Tibary, 2007).

The genital tracts were sampled taking 2-3 pieces from different tubular portions which were kept in $10 \%$ formaldehyde solution for 15 days, processed to paraffin, sectioned at $5 \mu \mathrm{m}$, and stained with hematoxylin and eosin stain for subsequent histological examination (Gherissi et al., 2018a). Finally, the histopathological features were identified and then verified by the boardcertified pathologist.

\section{Statistical analysis}

The prevalence of the endometrial gland anomalies associated to other genital tract abnormalities was calculated using Microsoft Office Excel 2013 (prevalence $\%=$ number of affected cases/total number of examined cases).

\section{Results}

\section{Prevalence of the congenital uterine anomalies}

The present study revealed two cases of congenital Müllerian duct anomalies among 165 studied female camels, i.e., a rate of $1.21 \%$. The endometrial gland agenesis was associated to aplasia of the left uterine horn in one case, and the endometrial glands dysgenesis was recorded with uterine infection representing a prevalence of $0.6 \%$ for each one.

\section{Cases description}

Endometrial gland agenesis and uterine horn aplasia The first uterine abnormality found in this study is the endometrial gland agenesis associated to aplasia of the left uterine horn. It was recorded in about 7-year-old nulliparous female camel weighing approximately $400 \mathrm{~kg}$. The studied female camel was reformed after three consecutive repeat breeding seasons. It comes from a transhumant herd composed of 28 females and one male dromedary camel. The slaughter period of the animal corresponded to the breeding season. The general examination of the animal showed that it had a body condition index (BCI) rating of 3.5 out of 5 . The uterine cervix was found in pelvic position with size length and diameter of about 6 and $4 \mathrm{~cm}$, respectively. The left uterine horn was totally absent (Fig. 1). The right contralateral uterine horn appeared to be normal with central lumen and well-developed tortuous oviduct attached to it. It had a firm consistency and positioned on the pubis floor. Its length and width were 16.4 and $6.3 \mathrm{~cm}$, respectively. The left oviduct communicated directly to the uterine body at the level of the uterine horns bifurcation (Fig. 1). The left and right oviducts had an approximate length and width of 19-20 $\mathrm{cm}$ and $3 \mathrm{~mm}$, respectively. They ended up in a well-developed bursa. Both the ovaries had normal morphology and were symmetrical in size. 

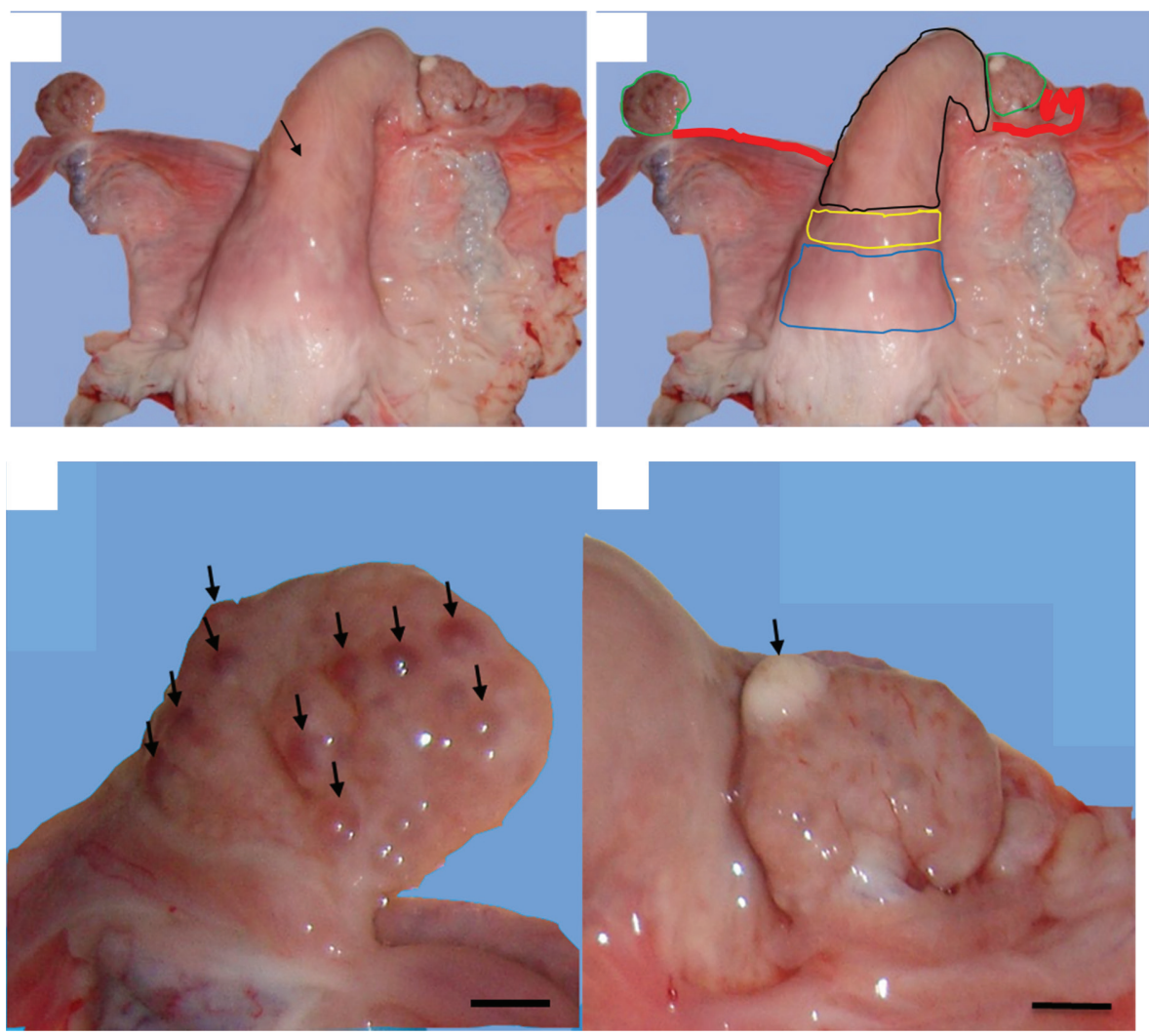

Fig. 1. Gross morphological aspect of female camel genital tract with unilateral uterine aplasia. (a) Lack of the left uterine horn and direct insertion of the left oviduct on the bifurcation of the uterine horns (arrow). (b) Genital organs; colored lines - blue: the cervix, yellow: uterine body, black: right uterine horn, red: oviducts, and green: ovaries. (c) Left ovary with small follicular structures (arrows). (d) Right ovary with atretic corpus luteum (arrow). (Scale bar: $1 \mathrm{~cm}$ ).

The left ovary was rough with numerous small follicles $(\approx 14)$ sized less than $5 \mathrm{~mm}$, whereas the right ovary had atretic corpus luteum (Fig. 1). After being dissected, the uterine body and the right uterine horn appear normal without any particular mucous content. The samples given by the studied female camels showed normal histological stratification of the contralateral uterine horn. However, the endometrial stroma was proliferated and did not show any endometrial glands (Fig. 2). A homogenous hyalinization of the myometrium was also recorded (Fig. 2).

\section{Endometrial gland dysgenesis and uterine infection}

The second uterine abnormality was the uterine gland dysgenesis associated to acute uterine infection. It was recorded in 4 $\frac{1}{2}$-year-old nulliparous female camel weighing approximately $300 \mathrm{~kg}$. The anamnesis stated that the she-camel reached the pubertal age at 3 years old and showed normal pattern of signs but reformed after two breeding seasons distinguished by repeat breeding syndrome. The slaughter period of the animal corresponded to the breeding season. The general examination showed that the female camel had a normal health conditions and BCI rating of 3 out of 5. The cervix and uterine horns had normal size and pelvic position. The uterine lumen contained serous exudate which was stained with blood. The uterus was hyperemic and edematous (Fig. 3). Both the ovaries had normal morphology and were symmetrical in size. Each ovary was found with one corpus luteum and without any follicular structures (Fig. 3). The uterine section showed sever dysgenesis of the endometrial glands, high infiltration by inflammatory cells, and proliferation and activation of endometrial stroma (Fig. 4). Focal vascular congestion was also observed on the endometrium (Fig. 4). The myometrium showed a focal infiltration by inflammatory cells (Fig. 4).

\section{Discussion}

We report, in this study, the first histopathological case with total agenesis of endometrial glands in female camels. A similar condition was communicated in riverine buffalo, ewes, bitch, and mare (Chethan et al., 2017; Dockweiler et al., 2017; Gray et al., 2002; Witkowski et al., 2017). It has been determined that this condition has genetic and/or hormonal backgrounds. Chromosomal aberrations, gene mutation or epigenetic strategies, both hormonal disturbances, and improper distribution of hormone receptors can result in 


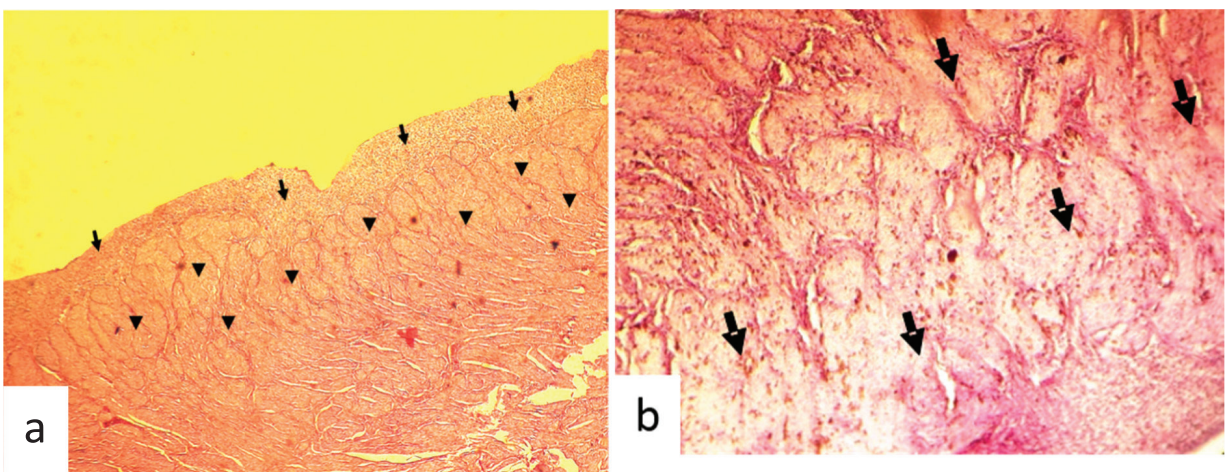

Fig. 2. Hematoxylin and eosin stained photographs of transversal sections of the remained uterus in female camel with unilateral uterine aplasia, showing a histopathologic aspect of the endometrium and the myometrium. (a) Endometrium with endometrial gland agenesis (arrows) and myometrium with hyalinization lesions (arrowheads) $(100 \times)$. (b) Hyalinization of the myometrial layer (arrows) (400×).
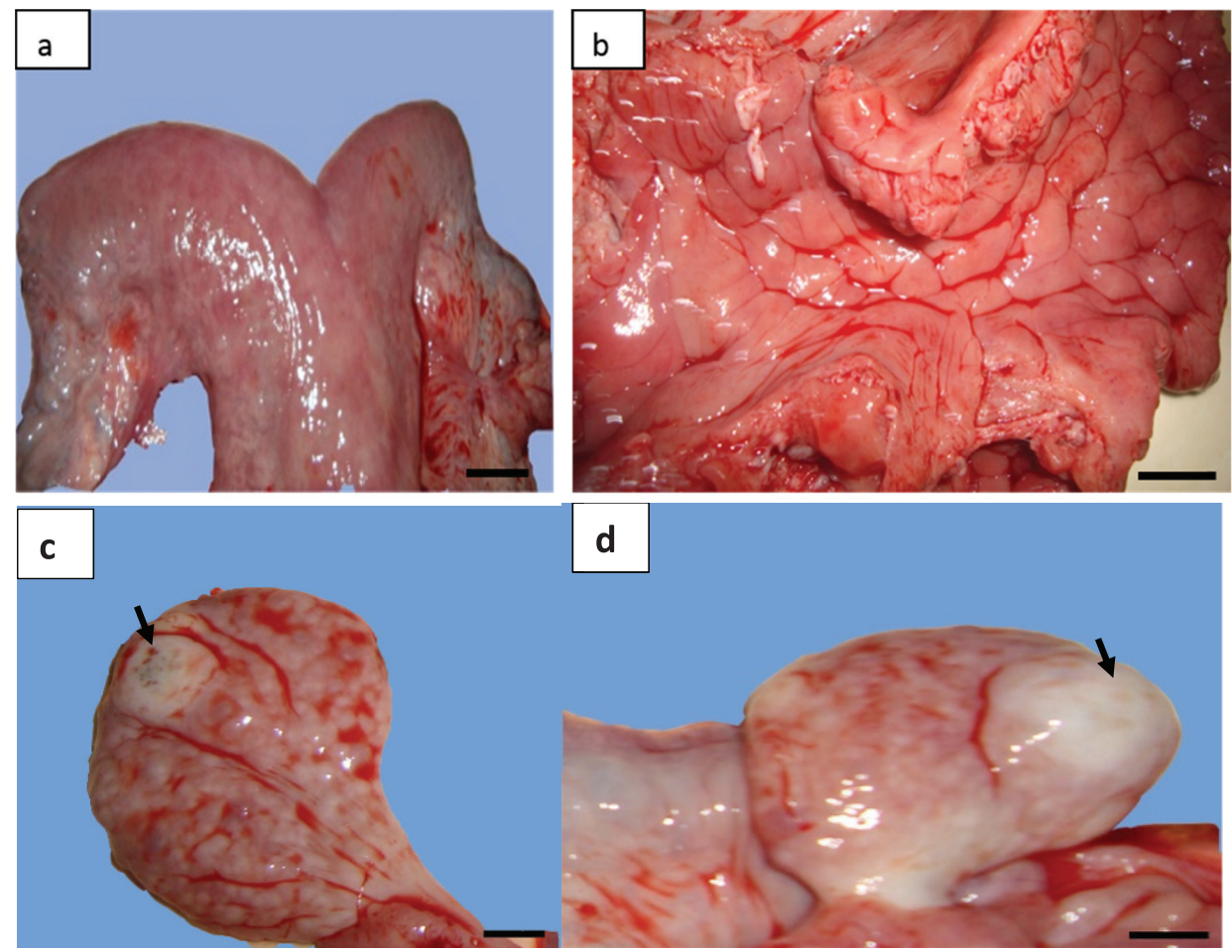

d

Fig. 3. (a) Gross morphology of genital tract and (b) the lumen of uterine horn of female camel with acute metritis. Both the (c) left and (d) right ovaries had normal morphology with atretic corpus luteum each one (arrows) (scale bar: $1 \mathrm{~cm}$ ).

incomplete adenogenesis or total UGKO (Chethan et al., 2017; Cooke et al., 2013; Emam, 2014; Gray et al., 2001a; Osman et al., 2018; Spencer et al., 2019). The uterus unicornis had been described in different farm animal species. This abnormality is also called uterine agenesis or segmental aplasia of the uterus. In the dromedary camel and other mammalian species, the etiology of this pathology is unknown (Colaço et al., 2012; Gherissi et al., 2019; Oh et al., 2005). A pleiotropic gene effect in cows has been observed
(Rendel, 1952). In this species, uterine agenesis is associated with the White Heifer Disease syndrome where the development defects of the Müllerian ducts (mesonephrotic) were noted (Hanzen, 2015b). Common associate feature, in this case, is often described as the imperforate hymen, absence of anterior part of the vagina, cervix or the uterine body, and developmental anomalies of the oviducts (Rendel, 1952).

Literature analysis showed only one case of unicornuate uterus reported by Tibary et al. (2001) in a clinical 


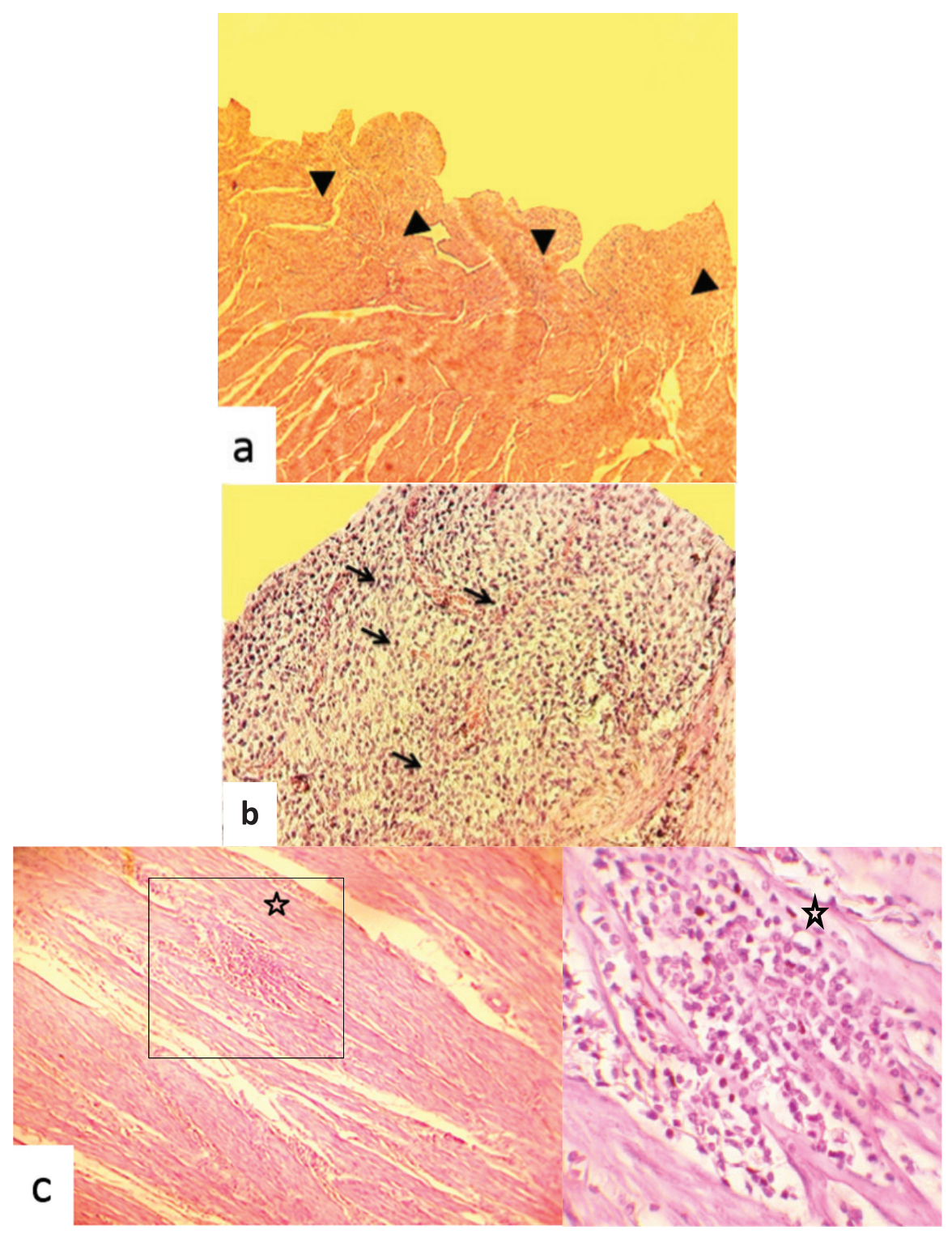

Fig. 4. Hematoxylin and eosin stained photographs of transversal sections of the uterine horn. (a) The endometrium showed dysgenesis of the endometrial glands (arrowheads) $(40 \times)$. (b) Highly proliferated and activated stroma, and infiltration by inflammatory cells of the endometrium (arrows) $(100 \times)$. (c) The myometrium showed focal infiltration by inflammatory cells (star) $(100 \times$ and $400 \times)$.

study conducted over 9 years looking for reproductive disorders in the female camel (cited by Faye and Esenov, 2005). Moreover, some studies on a large number of female camels in Egypt (El-Wishy, 1989; Shawky et al., 2004), Nigeria (Ribadu et al., 1991), Algeria (Benaissa et al., 2015; 2017), Ethiopia (Melaku et al., 2015), Iraq (Wajid, 2015), and Saudi Arabia (Ali et al., 2015) have not recorded cases of this abnormality. This being so the frequency of the uterine horn aplasia in camels is as low as in cows, small ruminants, and new world camelids (Tibary and Anouassi, 1997). The rate of this abnormality was estimated between $0.12 \%$ and
$0.45 \%$ in cows (Bos taurus) and buffalo (Bos bubalis) (Hatipoglu et al., 2002; Mimoune et al., 2016), 1.47\% in goat (Beena et al., 2015), 1.3\% in South American Camelids (Smith, 1985), and $0.05 \%$ in ewes (Smith et al., 1995). In ovine species, the uterus unicornis condition represents $1.8 \%$ of all developmental defects of paramesonephric ducts (Smith et al., 1995).

Similarly to the finding, the association between the uterine aplasia or aplastic segment of the uterus and lacked or attenuated endometrial glands in cats was reported by McIntyre et al. (2010). Thus, the endometrial components were not identified in 
histological evaluation of the abnormal horns and a fibrous mesenchymal tissue with some smooth muscle differentiation, and the blood vessels were present. Nevertheless, we did not note the association of the uterine agenesis with other congenital abnormalities of the genital tract segments in the studied female camel. This is not the case, particularly in the bovine species, where uterine agenesis could be associated with aplasia of other segments of the genital tract, namely, absence of the lumen of corpus uteri, cervix cyst, distension of the remained uterine horn, hydrosalpinx, narrow ductal vaginal appearance, blind sac on the level of cervix, and shorter corpus uteri (Hatipoglu et al., 2002). Likewise, associated lesions such as hydrometra of the remaining uterine horn, ovarian agenesis, and abnormal position of the contralateral ovary were reported in ovine species (Smith et al., 1995).

We reported, in this study, the association of uterine gland dysgenesis and uterine infection. Similar degeneration of the glandular compartment of the endometrium was reported in female camels with acute endometritis (Benaissa et al., 2015). This would recall the uterine mucus secretions from the endometrial glands as chemical defense mechanism against contaminant microorganisms (Dhaliwal et al., 2001). Disruption of this mechanism allows opportunistic pathogens to colonize the endometrium and cause an endometritis particularly with wrong mating as suggested by Ali (2010) in a nulliparous female camel. The endometrial gland dysgenesis was also reported to be correlated to the ovarian follicular dynamic that is highly decreased during the nonbreeding season (Ali et al., 2017; Gherissi et al., 2018b). The bibliographic data lack information on the incidence of endometrial adenogenesis and regeneration anomalies on the reproduction flow of camels. The clinical behavior of repeat breeding was recorded during the harvest of commemoratives. Female camels were reformed because of unexplained infertility, and their genital tract abnormalities were passed unnoticed. The endometrial gland anomalies would be causing the impediment of gestation by alteration of uterine receptivity, blastocyst/ conceptus survival and implantation, and stromal cell decidualization (Filant and Spencer, 2014; Gray et al., 2001b). The uterine aplasia in some mammal species as cat (Brookshire et al., 2017), cow (Moriyama et al., 2008), and mare (Gallacher and Gilbert, 2018) does not prevent pregnancy. In camelids, missing left uterine horn could lead to infertility as long as nearly all pregnancies occur in the left side (Ali et al., 2015; Gherissi et al., 2017; 2019; Tibary and Anouassi, 1997). Both cases of the genital anomalies had normal active ovaries. The anoestrus occurs if ovulation and corpus luteum are observed in the ipsilateral side of the missing horn (Hanzen, 2015b). Anyways, breeding of animals presenting such genital congenital affection is strongly discouraged because of the risk of genetic transmission of the abnormality (Tibary et al., 2001).
The congenital agenesis of the endometrial glands was observed as a rare genital anomaly associated to unilateral uterine aplasia. The endometrial gland dysgenesis was recorded in association to acute uterine infection. These uterine anomalies would lead to definitive sterility. We suggested that the histopathologic complementary assessment can be a reliable technique since the clinical history and standard genital examinations almost do not orientate to assess these congenital abnormalities. Hormonal and/or genetic examinations are highly recommended to diagnose and eliminate such animals.

\section{Conflict of interest}

The authors declare that there is no conflict of interest. Author's contribution

Gherissi Djallel Eddine, Bouzebda Afri Farida, and Bouzebda Zoubir designed the study. Gherissi Djallel Eddine performed the experiments. Gherissi Djallel Eddine, Lamraoui Ramzi, and Faycel Chacha analyzed the data and wrote the paper. Christian Hanzen helped in writing the manuscript.

\section{References}

Ali, A. 2010. Observations on the topography of the reproductive tract of the Arabian female camel. J. Agric. Vet. Sci. Qassim Univ. 3, 33-41.

Ali, A., Derar, R., Al-Sobayil, F., Al-Hawas, F. and Hassanein, K. 2015. A retrospective study on clinical findings of 7300 cases (2007-2014) of barren female dromedaries. Theriogenology. 84, 452-456.

Ali, H.M., Qureshi, A.S., Urbinati, G., Hussain, R., Mustafa, M.Z., Ali, F., Manan, A. and Massaad-Massade, L. 2017. Effects of natural environment on reproductive histo-morphometric dynamics of female dromedary camel. Anim. Reprod. 181, 30-40.

Azawi, O.I. and Ali, A.J. 2011. A study on the prevalence of some pathological abnormalities of the uterus diagnosed at post mortem of buffaloes in Mosul. Buffalo Bull. 30(1), 67-71.

Beena, V., Pawaiya, R.V.S., Shivasharanappa, N., Gururaj, K., Gupta, V.K., Gangwar, N.K., Singh, D.D., Karikalan, M., Sharma, A.K., Kumar, H., Kumar, A. and Singh, R. 2015. Occurrence of pathological conditions in the female genitalia of goats. Indian J. Vet. Pathol. 39(3), 197-201.

Benaissa, M.H., Faye, B. and Kaidi, R. 2015. Reproductive abnormalities in female camel (Camelus dromedarius) in Algeria: relationship with age, season, breed and body condition score. J. Camel Pract. Res. 22(1), 67-73.

Benaissa, M.H., Mimoune, N. and Kaidi, R. 2017. Prevalence and anatomohistopathologic studies of uterine anomalies in she-camels in southeast Algeria. Human Vet. Med. 9(4), 137-145.

Brookshire, W.C., Shivley, J., Woodruff, K. and Cooley, J. 2017. Uterus unicornis and pregnancy 
in two feline littermates. JFMS Open Rep. 3(2), 2055116917743614.

Carson, S.A., Simpson, J.L., Malinak, L.R., Elias, S., Gerbie, A.B., Buttram, V.C. and Sarto, G.E. 1983. Heritable aspects of uterine anomalies. II. Genetic analysis of Müllerian aplasia. Fertil. Steril. 40(1), 86-90.

Chethan, S.G., Singh, S.K., Karikalan, M., Kharayat, N.S., Behera, B.K., Narayanan, K. and Kumar, H. 2017. Congenital anomalies of the uterus in Riverine buffalo (Bubalus bubalis). Buffalo. Bull. 36(4), 581-587.

Colaço, B., Pires, M.A. and Payan-Carreira, R. 2012. Congenital aplasia of the uterine-vaginal segment in dogs. In A bird's-eye view of veterinary medicine. Ed., Perez-Marin, C.C. In Tech Open, pp: 165-178. DOI: $10.5772 / 31419$.

Connell, M., Owen, C. and Segars, J. 2013. Genetic syndromes and genes involved in the development of the female reproductive tract: a possible role for gene therapy. J. Genet. Syndr. Gene Ther. 4, 127; doi:10.4172/2157-7412.1000127.

Cooke, P.S., Spencer, T.E., Bartol, F.F. and Hayashi, K. 2013. Uterine glands: development, function and experimental model systems. Mol. Hum. Reprod. $19,547-558$.

Demir, B., Guven, S., Guvendag Guven, E.S. and Gunalp, G.S. 2007. An incidental finding of unicornuate uterus with unilateral ovarian agenesis during cesarean delivery. Arch. Gynecol. Obstet. 276(1), 91-93.

Dhaliwal, G.S., Murray, R.D. and Woldehiwet, Z. 2001. Some aspects of immunology of the bovine uterus related to treatments for endometritis. Anim. Reprod. Sci. 67, 135-152.

Dockweiler, J.C., Cossic, B., Donnelly, C.G., Gilbert, R.O., Buckles, E. and Cheong, S.H. 2017. Infertility associated with the absence of endometrial progesterone receptors in a bitch. Reprod. Domest. Anim. 52(1), 174-178.

El-Wishy, A.B. 1989. Genital abnormalities of the female dromedary (Camelus dromedurius). An abattoir survey. Reprod. Domest. Anim. 24, 84-87.

Emam, M.A. 2014. Immunohistochemical localization of androgen and progesterone receptors in the uterus of the camel (Camelus dromedarius). Acta. Histochem. 116, 1225-1230.

Faye, B. and Esenov, P. 2005. Factors affecting reproductive performance of camels at the herd and individual level. In Desertification combat and food safety: the added value of camel producers. Eds., Tibary, T., Anouassi, A. and Sghiri, A. NATO Science Series, I: Life and Behavioural Sciences, vol. 362, pp. 97-114.

Faye, B.M., Bengoumi, A., Cleradin, A., Tabarani, A. and Chilliard, Y. 2001. Body condition score in dromedary camel: a tool for management of reproduction. In Proceedings of the International Twin Conference on Reproduction/Production in Camelids, Al-Ain, U.A.E. Emir. J. Agric. Sci. 13, 1-6.

Filant, J. and Spencer, T.E. 2014. Uterine glands: biological roles in conceptus implantation, uterine receptivity, and decidualization. Int. J. Dev. Biol. $58,107-116$.

Floyd, J.G., McElhenney, W.H., Heath, A.M., Blaylock, R.E., Norris, B.E., Pegues, M.D., Carson, R.L., Coleman, D.A. and Bartol, F.F. 2001. Fertility of beef heifers treated from birth with growth promoting implants. In ASAS Southern Section Abstracts. 5 (abstract 15).

Gallacher, K. and Gilbert, R.O. 2018. Case report: successful foaling in a Warmblood mare with uterus unicornis. Clin. Theriogenol. 10, 51-58.

Gerstenberg, C., Allen, W.R. and Stewart, F. 1999. Cell proliferation patterns during development of the equine placenta. J. Reprod. Fertil. 117, 143-152.

Gherissi, D.E., Afri-Bouzebda, F. and Bouzebda, Z. 2017. Gestational age estimation of Sahraoui dromedary camel based on fetomaternal measures and phenotypic characteristics. J. Anim. Vet. Adv. 16(2), 32-39.

Gherissi, D.E., Afri-Bouzebda, F. and Bouzebda, Z. 2018a. Seasonal changes in the testicular morphology and interstitial tissue histomorphometry of Sahraoui camel under Algerian extreme arid conditions. Biol. Rhythm Res. 49(2), 1-11.

Gherissi, D.E., Afri-Bouzedba, F., Bouzebda, Z. and Bonnet, X. 2018b. Are female camels capital breeders? Influence of seasons, age, and body condition on reproduction in an extremely arid region. Mamm. Biol. 93, 124-134.

Gherissi, D.E., Bouzebda, Z., Bouzebda Afri, F., Lamraoui, R. and Chacha, F. 2019. Cross-sectional survey of congenital and acquired genital disorders in Sahraoui female camels (Camelus dromedarius) at El Oued abattoir, south-east Algeria. Anim. Res. Int. 16(3), 3450-3462.

Golan, A., Langer, R., Bukovsky, I. and Caspi, E. 1989. Congenital anomalies of the mullerian system. Fertil. Steril. 51(5), 747-755.

Gray, C.A., Bartol, F.F., Tarleton, B.J., Wiley, A.A., Johnson, G.A., Bazer, F.W. and Spencer, T.E. 2001a. Developmental biology of uterine glands. Biol. Reprod. 65(5), 1311-1323.

Gray, C.A., Bartol, F.F., Taylor, K.M., Wiley, A.A., Ramsey, W.S., Ott, T.L., Bazer, F.W. and Spencer, T.E. 2000. Ovine uterine gland knock-out model: effects of gland ablation on the estrous cycle. Biol. Reprod. 62, 448-456.

Gray, C.A., Burghardt, R.C., Johnson, G.A., Bazer, F.W. and Spencer, T.E. 2002. Evidence that absence of endometrial gland secretions in uterine gland knockout ewes compromises conceptus survival and elongation. Reproduction. 124, 289-300.

Gray, C.A., Taylor, K.M., Ramsey, W.S., Hill, J.R., Bazer, F.W., Bartol, F.F. and Spencer, T.E. 2001b. 
Endometrial glands are required for preimplantation conceptus elongation and survival. Biol. Reprod. 64(6), 1608-1613.

Hanzen, C. 2015a. Sémiologie: La propédeutique de l'appareil génital femelle des ruminants. Documents pédagogiques: Notes de cours et syllabus. Université de Liège. Available via https:// orbi.uliege.be/bitstream/2268/70541/1/R03_ Proped_genitale_femelle_2016.pdf

Hanzen, C. 2015b. L'anoestrus pubertaire et du post-partum dans l'espèce bovine. Documents pédagogiques: Notes de cours et syllabus. Université de Liège. Available via www.therioruminant.ulg. ac.be/notes/200809/R09_Anoestrus_bovin_2009 PWP.pdf

Hatipoglu, F., Ortatatli, M., Kiran, M.M., Erer, H. and Ciftci, M.K. 2002. An abattoir study of genital pathology in cows:II. Uterus, Cervix and Vagina. Revue. Med. Vet. 152(2), 93-100.

Haydardedeoglu, B., Simsek, E., Kilicdag, E.B., Tarim, E., Aslan, E. and Bagis, T. 2006. A case of unicornuate uterus with ipsilateral ovarian and renal agenesis. Fertil. Steril. 85(3), 750.e1-750.e4.

Jeong, J.W., Kwak, I., Lee, K.Y., Kim, T.H., Large, M.J., Stewart, C.L., Kaestner, K.H., Lydon, J.P. and DeMayo, F.J. 2010. Foxa2 is essential for mouse endometrial gland development and fertility. Biol. Reprod. 83, 396-403.

Jeong, J.W., Lee, H.S., Franco, H.L., Broaddus, R.R., Taketo, M.M., Tsai, S.Y., Lydon, J.P. and DeMayo, F.J. 2009. Beta-catenin mediates glandular formation and dysregulation of beta-catenin induces hyperplasia formation in the murine uterus. Oncogene. 28, 31-40.

Massé, J., Watrin, T., Laurenta, A., Deschamps, S., Guerrier, D. and Pellerin, I. 2009. The developing female genital tract: from genetics to epigenetics. Int. J. Dev. Biol. 53, 411-424.

McIntyre, R.L., Levy, J.K., Roberts, J.F. and Reep, R.L. 2010. Developmental uterine anomalies in cats and dogs undergoing elective ovariohysterectomy. J. Am. Vet. Med. Assoc. 237(5), 542-546.

Melaku, S.K., Melaku, M., Feyisa, A., Demissie, T., Regassa, F., Mekonnen, G.A., Almaw, G., Tessema, T.S., Kassa, T. and Dawo, F. 2015. Pathological and bacteriological study on abnormalities of female internal reproductive organ of Camelus dromedarius slaughtered at Akaki abattoir, Ethiopia. American-Eurasian J. Sci. Res. 10(4), 193-202.

Miller, C. and Sassoon, D.A. 1998. Wnt-7a maintains appropriate uterine patterning during the development of the mouse female reproductive tract. Develop. 125, 3201-3211.

Mimoune, N., Kaidi, R., Azzouz, M.Y., Keddour, R., Belarbi, A. and Derdour, S.Y. 2016. Genital tract pathologies of cows slaughtered at El-Harrach abattoir in Algeria. Kafkas Univ. Vet. Fak. Derg. 22(5), 639-646.
Moriyama, C., Kobayashi, I., Tani, M., Oishi, T., Kajisa, M., Horii, Y. and Kamimura, S. 2008. Case of pregnancy in two cows with unicorn horn of the uterus either by artificial insemination at ipsilateral or embryo transfer at contralateral Corpus luteum in the Ovary. Reprod. Domest. Anim. 43(3), 382-384.

Mülayim, B., Demirbasoglu, S. and Oral, O. 2003. Unicornuate uterus and unilateral ovarian agenesis associated with pelvic kidney. Surg. Endosc. 17(1), 161.

Oh, K.S., Son, C.H., Kim, B.S., Hwang, S.S., Kim, Y.J., Park, S.J., Jeong, J.H., Jeong, C., Park, S.H. and Cho, K.O. 2005. Segmental aplasia of uterine body in an adult mixed breed dog. J. Vet. Diagn. Invest. 17, 490-492.

Osman, A.K., Abbott, L.C. and Ahmed, A.A.M. 2018. Survey of nuclear progesterone receptor expression in the uterus of the cyclic and pregnant camel (Camelus dromedarius). Anat. Histol. Embryol. 47(6), 544-550.

Rendel, J.M. 1952. White heifer disease in a herd of dairy Shorthorn. J. Genet. 51(1), 89-94.

Ribadu, A.Y., Ogwu, D., Njokut, C.O. and Eduviet, L.O. 1991. Abattoir survey of female genital disorders of imported camels (Camelus dromedarius) in Kano, Nigeria. Br. Vet. J. 147(2), 90.

Roberts, S.J. 1971. Infertility the cow: veterinary obstetrics and genital diseases, 2nd Ed. Ithaca, New York, pp. 464-465.

Shawky, A.M., Tantawy, A.A. and Ibrahim, M.F. 2004. An abattoir survey of female genital disorders of camels (Camelus dromedaries) in Kalyoubia , Egypt. 1st Annual Conference, FVM., Moshtohor, Sept, 2004.

Shulman, L.P. and Elias, S. 1988. Developmental abnormalities of the female reproductive tract: pathogenesis and nosology. Acta Obstet. Gynecol. Scand. 67, 441.

Smith, K.C., Long, S.E. and Parkinson, T.J. 1995. Congenital abnormalities of the ovine paramesonephric ducts. Br. Vet. J. 151, 443-451.

Smith, T.I.M. 1985. Reproduction in South American Camelids. Iowa State Univ. Vet. 47(2), 6. Available via https://lib.dr.iastate.edu/iowastate_veterinarian/ vol47/iss $2 / 6$

Spencer, T.E., Kelleher, A.M. and Bartol, F.F. 2019. Development and Function of Uterine Glands in Domestic Animals. Annu. Rev. Anim. Biosci. 7, 125-147.

Tibary, A. 2007. Breeding soundness evaluation and subfertility in female llamas and alpacas. In: Youngquist R., Threlfall W., eds. Current therapy in large animal theriogenology. 2nd ed., Saunders/ Elsevier, St. Louis, MO, pp. 878-883.

Tibary, A. and Anouassi, A. 1997. Theriogenology in camelidae. anatomy, physiology, pathology and 
artificial breeding. 1st ed., Abu Dhabi Printing and Publishin Company, Mina, Abu Dhabi, UAE.

Tibary, A., Anouassi, A. and Memon, M.A. 2001. Approach to diagnosis of infertility in camelids: retrospective study in alpaca, lamas and camels. J. Camel Pract. Res. 8, 167-179.

Verp, M.S., Simpson, J.L., Elias, S., Carson, S.A., Sarto, G.E. and Feingold, M. 1983. Heritable aspects of uterine anomalies. I. Three familial aggregates with Müllerian fusion anomalies. Fertil. Steril. 40(1), 80-85.

Wajid, S.J. 2015. A pathological abattoir survey of the reproductive tracts of non pregnant camels
(Camelus dromedaries) in Iraq. IOSR J. Pharm. Biol. Sci. 10, 84-90.

Warot, X., Fromental-Ramain, C., Fraulob, V., Chambon, P. and Dollé, P. 1997. Gene dosagedependent effects of the Hoxa-13 and Hoxd-13 mutations on morphogenesis of the terminal parts ofthe digestive and urogenital tracts. Develop. 124, 4781-4791.

Witkowski, M., Katkiewicz, M., Kochan, J. and Panzani, D. 2017. Uterine glands agenesia in the mare. J. Equine Vet. Sci. 58, 47-50. 